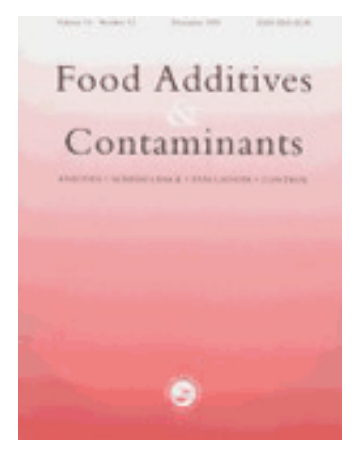

\title{
Carry-over of pyrrolizidine alkaloids from feed to milk in dairy cows
}

\begin{tabular}{|c|c|}
\hline Journal: & Food Additives and Contaminants \\
\hline Manuscript ID: & TFAC-2010-184.R1 \\
\hline Manuscript Type: & Special Issue \\
\hline $\begin{array}{l}\text { Date Submitted by the } \\
\text { Author: }\end{array}$ & $18-O c t-2010$ \\
\hline Complete List of Authors: & $\begin{array}{l}\text { Hoogenboom, Ron; RIKILT Institute of Food Safety, Wageningen } \\
\text { UR, Bioanalysis and Toxicology } \\
\text { Mulder, Patrick; RIKILT Institute of Food Safety, Wageningen UR, } \\
\text { Residue and Contaminant Analysis } \\
\text { Zeilmaker, Marco; RIVM, SIR } \\
\text { van den Top, Hester; RIKILT Institute of Food Safety, Wageningen } \\
\text { UR, Residue and Contaminant Analysis } \\
\text { Remmelink, Gerrit; ASG, Livestock Research } \\
\text { Brandon, Esther; RIVM, SIR } \\
\text { Klijnstra, Mirjam; RIKILT Institute of Food Safety, Wageningen UR, } \\
\text { Residue and Contaminant Analysis } \\
\text { Meijer, Gerwin; ASG, Livestock Research } \\
\text { Schothorst, Ronald; RIVM, SIR } \\
\text { van Egmond, Hans; RIKILT Institute of Food Safety, Wageningen } \\
\text { UR, Residue and Contaminant Analysis }\end{array}$ \\
\hline Methods/Techniques: & $\begin{array}{l}\text { Chromatography - LC/MS, Toxicology - pharmokinetics, Risk } \\
\text { assessment - modelling }\end{array}$ \\
\hline Additives/Contaminants: & Natural toxicants - alkaloids, Mutagenic compounds \\
\hline Food Types: & Animal feedingstuffs, Milk \\
\hline
\end{tabular}




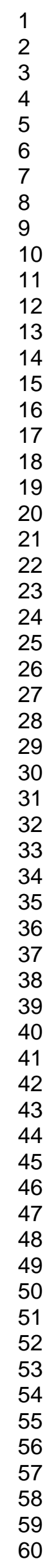

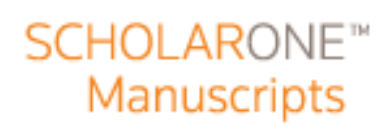

7

25

26

27

29

30

32

33

34

35

36

37

39

40

41

42

44

45

46

47

48

50

51

52

53

54

56

57

58

60

http://mc.manuscriptcentral.com/tfac Email: fac@tandf.co.uk 


\section{Carry-over of pyrrolizidine alkaloids from feed to milk in dairy cows} 3

4 L.A.P. Hoogenboom ${ }^{1}$, P.P.J. Mulder ${ }^{1}$, M.J. Zeilmaker ${ }^{2}$, H.J. van den Top ${ }^{1,2}$, G.J. Remmelink ${ }^{3}$, 5 E.F.A. Brandon ${ }^{2}$, M. Klijnstra ${ }^{1}$, G.A.L. Meijer ${ }^{3}$, R. Schothorst ${ }^{2}$ and H.P. van Egmond ${ }^{1,2}$ 6

71 RIKILT Institute of Food Safety, Wageningen UR, P.O. Box 230, 6700 AE Wageningen, $8 \quad$ The Netherlands

92 RIVM National Institute for Public Health and the Environment, Bilthoven, The $10 \quad$ Netherlands

113 ASG Livestock Research, Wageningen UR, P.O. Box 65, 8200 AB Lelystad, The 12 Netherlands

13 


\section{Abstract}

16 Pyrrolizidine alkaloids (PAs) are toxins present in many plants belonging to the families of

17 Asteraceae, Boraginaceae and Fabaceae. Particularly notorious are PAs present in ragwort

18 species (Senecio), which are held responsible for hepatic disease in horses and cows and may

19 lead to the death of the affected animals. In addition, these compounds may be transferred to

20 edible products of animal origin and as such be a threat for the health of consumers.

21 To investigate the possible transfer of PAs from contaminated feed to milk, cows were

22 put on a ration for 3 weeks with increasing amounts (50-200 $\mathrm{g} \mathrm{day}^{-1}$ ) of dried ragwort. Milk

23 was collected and sampled twice a day, faeces and urine twice a week. For milk, a dose-

24 related appearance of PAs was found. Jacoline was the major component in milk despite

25 being a minor component in the ragwort material. Practically no $\mathrm{N}$-oxides were observed in

26 milk, notwithstanding the fact that they constituted over $80 \%$ of the PAs in ragwort. The

27 overall carry-over of the PAs was estimated to be only around $0.1 \%$, but for jacoline $4 \%$.

28 Notwithstanding the low overall carry-over, this may be relevant for consumer health

29 considering the genotoxic and carcinogenic properties demonstrated for some of these

30 compounds. Analysis of the faeces and urine samples indicated that substantial metabolism of

31 PAs is taking place. The toxicity and potential transfer of metabolites to milk is unknown and

32 remains to be investigated.

34 Keywords: pyrrolizidine alkaloids, cows, milk, jacoline, ragwort, analysis, carry-over,

35 Senecio 


\section{Introduction}

Pyrrolizidine alkaloids (PAs) are toxic compounds present in many plants belonging to the families of Asteraceae (Compositae), Boraginaceae and Fabaceae (Leguminosae). Important members of the Asteraceae family are ragwort (Jacobeae vulgaris, syn. Senecio jacobeae) and common groundsel (Senecio vulgaris). Hundreds of different PAs have been isolated and characterised from a broad range of PA-containing plants (Molyneux and James 1990; EFSA 2007; Hartmann and Witte 1995). PAs are composed of a necine base and one or two ester groups or a macrocyclic diester. Figure 1 shows some important representatives. Even within one species there may be more than 10 different PAs present (Hartmann and Witte 1995; Joosten et al. 2009, 2010). Furthermore, the composition (and concentration) may fluctuate with respect to climate and environmental conditions, the age and part of the plant, and the variety (genotype/chemotype). The PAs in ragwort and groundsel are generally of the macrocyclic diester type and in the $\mathrm{N}$-oxide form, but can be easily reduced to a tertiary amine (Hartmann and Toppel 1986; Lindigkeit et al. 1997).

In a number of countries, like the Netherlands, the incidence of ragwort appears to be increasing. Due to their bitter taste, PA-containing plants are generally unpalatable and normally avoided by grazing animals in the field. However, in preserved and composed feeds, this recognition is lost and the toxic PAs may be consumed by livestock. PAs for long have been recognized as toxic for livestock (Bull et al. 1968), causing serious effects on the liver which may eventually cause the death of the animal. Nevertheless they have not been listed as undesirable substances and thus far the European Commission has not established permitted levels for PAs in animal feed stuffs.

PAs may also endanger human health either directly by consumption of PA-containing plants but also indirectly through animal derived food products. Various PAs have been shown to have genotoxic properties and to cause tumours in rodents (Fu et al. 2004; EFSA 
61 2007). As a result it might be assumed that there is no threshold for these effects, meaning

62 that even a small dose may potentially cause tumours. EFSA did not draw this conclusion, 63 based on the fact that no epidemiological studies have been performed to show that exposure 64 to PAs results in increased cancer cases in humans (EFSA 2007). The National Institute for 65 Public Health and the Environment (RIVM) of the Netherlands used a linear extrapolation to 66 arrive at the dose corresponding to an increased risk of 1 extra cancer case per million people 67 exposed, being $30 \mathrm{ng}$ per person per day (virtual safe dose or VSD) (van der Zee 2005). This 68 VSD is derived from a rat study with riddelliine but there are no studies to show whether a 69 VSD for other PAs would be different. Regarding this very low VSD, it is essential to 70 evaluate the potential risk of ragwort and related plants for the consumer.

71 Various studies have been performed to study the presence of PAs in honey, showing 72 significant levels in some retail honey and especially when honey is collected near fields with 73 PA containing plants (Crews et al. 1997; Edgar et al. 2002; Boppré 2008). PAs may also be 74 present in other food products like milk. In order to evaluate the potential transfer of PAs 75 from feed stuffs to milk, Dickinson et al. (1976) dosed 4 lactating cows via rumen fistula with 764 to $5 \mathrm{~kg}$ of dried ragwort (corresponding to $10 \mathrm{~g} \mathrm{~kg}^{-1}$ body weight per day) for a period of 5-7 77 days and then gradually decreased the dose by 50-75\% after 14-26 days. The PA content of 78 the dried material was $1.5 \mathrm{~g} \mathrm{~kg}^{-1}$. The relatively high dosage in this experiment resulted in a 79 decrease in both body weight and milk production after 5 days. Livers of the animals were 80 clearly affected by the treatment. Concentrations determined in milk were in the range of $81470-840 \mu \mathrm{g} \mathrm{l}^{-1}$. Due to the limited availability of standards, only a few PAs could be detected 82 in the ragwort, like jacobine, seneciphylline, jacoline, jaconine and jacozine. N-oxides were 83 not analysed for in this study. Jacoline was the only PA identified in the milk. Taking into 84 account the amount of ragwort fed to the cows, the milk yield and the PA concentrations in 85 ragwort and milk, it was calculated that about $0.1 \%$ of the PAs was transferred to the milk. 
86 Deinzer et al. (1982) carried out a study on milk of goats dosed via a rumen cannula with $10 \mathrm{~g}$ 87 dried ragwort per kg bw per day. The PA content of the ragwort was estimated at $3 \mathrm{~g} \mathrm{~kg}^{-1} \mathrm{dry}$ weight. Using a gas chromatographic method that was based on the reduction of all free bases to a single derivative of retronecine, a total PA content in the milk of 330 to $810 \mu \mathrm{g} \mathrm{l}^{-1}$ was reported. The transfer to milk was estimated to be around $0.1 \%$ of the daily dose. The authors 91 also did not consider or investigate the possible presence of $\mathrm{N}$-oxides in the ragwort material, 92 nor in the milk.

93 Although these studies indicate that the transfer could be relatively small, the eventual 94 concentrations in milk may still present a considerable risk for the consumer. The VSD 95 described above would be reached by a livelong daily consumption of only $0.1 \mathrm{ml}$ of the milk 96 from the Dickinson and Deinzer studies. However, the animals in these studies received 97 unrealistic high levels of ragwort. On the other hand, not all PAs were analysed, like the N98 oxides which normally constitute the majority of the alkaloids present in plant material.

99 Molyneux and James (1990) reviewed the existing data and pointed to the possibility that in 100 addition to the free bases also the $\mathrm{N}$-oxides might be transferred to milk and actually be 101 responsible for at least a part of the toxic effects observed in animals given milk from exposed 102 mother animals. Therefore it was decided to improve the analytical methods to determine PAs 103 and to repeat the Dickinson study using much lower levels of ragwort, unlikely to cause 104 adverse effects in the animals. The present paper confirms that jacoline was the major PA in 105 ragwort transferred to the milk, although it was only a minor component in the plant material 106 itself. At the same time the study indicates that a major part of the PAs is metabolized 107 possibly resulting in metabolites that are still a potential health hazard to the consumer. 


\section{Materials and Methods}

109

\section{Materials}

111 Analytical samples of a number of PA tertiary amine standards (senecionine, seneciphylline,

112 retrorsine, senkirkine, otosenine, heliotrine) were obtained from commercial sources

113 (Phytolab, Vestenbergsgreuth, Germany; Phytoplan, Heidelberg, Germany; Latoxan, Valence,

114 France). Jacobine, jacoline, erucifoline and florosenine were isolated from plant material by

115 PRISNA (Leiden, The Netherlands). Integerrimine was a gift from Dr. Trigo (UNICAMP,

116 Campinas, Brasil). Riddelliine and riddelliine-N-oxide were a gift from Dr. Chou (NCTR,

117 Jefferson, AR, USA). Acetylseneciphylline was prepared by acetylation of seneciphylline

118 with acetic anhydride and pyridine. N-oxides of senecionine, seneciphylline, retrorsine,

119 integerrimine, acetylseneciphylline, jacobine and erucifoline were prepared by N-oxidation of

120 the corresponding tertiary amines with $30 \%$ hydrogen peroxide according to Chou et al.

121 (2003). N-oxide standards of senecionine, seneciphylline and retrorsine have recently become

122 available from the above mentioned vendors as well. The standards were at least $90 \%$ pure

123 according to LC-MS/MS analysis. In total a set of 20 reference standards was available for 124 this study.

125 Adult plants of ragwort (Jacobaea vulgaris, syn. Senecio jacobaea) and narrow-leaved

126 ragwort (Senecio inaequidens) were collected during June and July 2008 at various sites

127 around Wageningen and Nijmegen in The Netherlands. The materials were subsequently air

128 dried, cut into pieces, ground to $1 \mathrm{~mm}$ with a Peppink 200 AN grinding machine (Veerman,

129 Olst, The Netherlands), and homogenized. In total $16.6 \mathrm{~kg}$ of dry material was produced,

130 being a mixture of $84 \%$ ragwort and $16 \%$ narrow-leaved ragwort. The material was stored in

131 the dark at room temperature.

132 
133

134

135

136

137

138

139

140

141

142

143

144

145

146

147

148

149

150

151

152

153

154

155

156

157

\section{Animal treatment}

Three dairy cows (Holstein Friesians) were treated at the Waiboerhoeve in Lelystad (part of Livestock Research, Wageningen UR). Animals were 4-5 years of age, weighed 600-700 kg and were fistulated in the rumen. Cows produced around 40 litres of milk per day.

Throughout the experiment they received a diet of grass and corn silage $(60 / 40 \mathrm{w} / \mathrm{w})$ and in addition soy and minerals. The treatment period consisted of five phases, each lasting one week. In week 1, animals received no ragwort (adaptation/control period), in week 2 they received two daily doses of $25 \mathrm{~g}$, in week 3 two daily doses of $50 \mathrm{~g}$, in week 4 two daily doses of $100 \mathrm{~g}$ and in week 5 no ragwort (depletion period). The dried ragwort was introduced directly into the rumen through the fistula in the morning and afternoon just after milking. Milk was collected twice daily around 6.00 and 16.30. In addition, urine and faeces samples were taken twice a week between 10.30-12.30, 4-6 hours after dosage of the ragwort. Milk, urine and faeces samples were kept frozen at $-20^{\circ} \mathrm{C}$ until analysis. The experimental plan was evaluated by an ethical committee prior to the study. The health of the animals was closely monitored by a veterinarian. One cow experienced mastitis during week 2 . Another cow encountered a brief period of indigestion at the end of week 4 . Both cows were treated with standard medication.

\section{Chemical analysis}

LC-MS/MS was used for the detection and quantification of PAs in biological matrices such as plant material, milk, urine and faeces. It allows the simultaneous detection of both forms of PAs, the free base (tertiary amine) and the N-oxide form (Xiong et al. 2009a; Joosten et al. 2010; Crews et al. 2010). LC-MS/MS is a very selective and sensitive technique capable to detect compounds at low concentrations. In milk, sub-ng $\mathrm{ml}^{-1}$ to $\mathrm{ng} \mathrm{ml}^{-1}$ concentrations were expected to be present, considering the relatively low dosing regime and the reported low 
158 transfer rate to milk. Therefore milk samples were concentrated prior to analysis. Urine and

159 faeces samples were purified by an solid phase extraction (SPE) procedure to remove matrix

160 interferences. PA concentrations in the plant material were relatively high. To obtain samples

161 that contained PAs in concentrations matching with the linear range of the mass spectrometer,

162 the plant extracts were diluted. No additional clean-up by SPE was necessary.

163

164 Analysis of ragwort

165 The analysis of the homogenised plant material was conducted according to the method

166 described by Joosten et al. (2010). To assess the PA composition and homogeneity of the

167 dried ragwort material, 14 samples (5-10 g) were randomly taken from the homogenized

168 material. From each sample two subsamples of $0.5 \mathrm{~g}$ were taken and transferred to $50 \mathrm{ml}$ test

169 tubes. Heliotrine $\left(100 \mu \mathrm{l}\right.$ of a $100 \mu \mathrm{g} \mathrm{ml}^{-1}$ solution in methanol) was added as internal

170 standard. Twenty-five $\mathrm{ml}$ of a $2 \%$ formic acid solution in water was added and the samples

171 were extracted by rotary tumbling for $1 \mathrm{~h}$. The extracts were filtered over a glass microfiber

172 filter (Whatman 1820-150). A $25 \mu 1$ aliquot was taken from the resulting clear extract,

173 transferred to an HPLC vial and mixed with $975 \mu 1$ of a $10 \mathrm{mM}$ ammonia solution in water.

174 The sample extracts were injected on the LC-MS/MS in a randomized order. Quantification

175 was performed with internal standard correction against a 6-point calibration curve of PA

176 standards $\left(0-500 \mathrm{ng} \mathrm{ml}^{-1}\right)$ in a diluted extract of tansy (Tanacetum vulgare). The extract of

177 tansy was prepared the same way as the ragwort extracts and was used to mimic a blank plant

178 extract. Homogeneity was checked by means of the ANOVA method described by Fearn and

179 Thompson (2001). The material was found sufficiently homogeneous. Relative standard

180 deviations for the concentrations obtained were generally less than $10 \%$ for the major

181 components and less than $15 \%$ for the minor components. Although the plant extracts were

182 diluted 40 times to match the concentration of the major components with the linear range of 
183 the MS detector, many minor components could be adequately detected and quantified. The

184 limit of quantification (LOQ) for the individual PAs and their N-oxides in dried plant material 185 was between 0.2 and $0.5 \mu \mathrm{g} \mathrm{g}^{-1}$.

187 Analysis of milk

188 The PA content in milk was assessed by means of LC-MS/MS according to an in-house

189 validated protocol (van den Top 2007). In short, test portions of $3.0 \mathrm{ml}$ of thawed milk were

190 transferred to test tubes and stored for at least 4 hours at $-20^{\circ} \mathrm{C}$. After the samples were

191 allowed to thaw at room temperature, $7.0 \mathrm{ml}$ of methanol containing $0.1 \%$ formic acid was

192 added and the samples were mixed well. The mixtures were again placed at $-20^{\circ} \mathrm{C}$ for at least

1934 hours. They were taken from the freezer and immediately centrifuged (10 min at 1950g,

$1944^{\circ} \mathrm{C}$ ) to obtain clear supernatants. From the supernatants $5.0 \mathrm{ml}$ was taken and evaporated to

195 dryness under a gentle stream of nitrogen at $55^{\circ} \mathrm{C}$. The dried residues were resuspended by

196 vortex mixing in $600 \mu \mathrm{l}$ water containing $0.1 \%$ acetic acid and subsequently centrifuged at

$1971950 \mathrm{~g}$ for $10 \mathrm{~min}$. An aliquot $(300 \mu \mathrm{l})$ was filtered over a $0.45 \mu \mathrm{m}$ Eppendorf filter and

198 transferred to an HPLC vial. The sample extracts were analysed using LC-MS/MS and

199 quantified against a 5-point calibration curve of PA standards in $0.1 \%$ acetic acid in water.

200 During the analytical sessions, duplicate determinations for some test portions were

201 performed and to all milk test portions and heliotrine was added at $100 \mathrm{ng} \mathrm{ml}^{-1}$ as an internal

202 standard to correct for recovery. Blanks (determination without test portion) were performed

203 at regular intervals. Method recovery percentages per day were used to correct for recovery.

204 The results of the duplicate determinations were within the expected variability (measurement

205 uncertainty at validation level ranged from 44 to $67 \%$ ). In the blanks no PAs were found. All

206 samples of evening milk were analysed in single. The samples of the evening milk taken

207 during the period of the highest dosage were analysed a second time, together with the milk 
208 collected in the morning. Results presented for the evening milk are the average of the 209 duplicates. The LOQ in milk for the individual PAs and their N-oxides was between 0.05 and $210 \quad 0.2 \mu \mathrm{g} \mathrm{l}^{-1}$.

\section{Analysis of urine and faeces}

213 The analysis of PAs in urine and faeces was based on an in-house validated method for the

214 determination of PAs in animal forage (Oosterink and Mulder 2008). Central part of this

215 method is the use of SPE for purification and concentration of the sample extracts. The SPE

216 clean-up step developed for forage could be used without modifications for urine and faeces.

217 Matrix matched standards together with heliotrine as an internal standard were incorporated in

218 the method to correct for differences in recovery and matrix effects.

219 Urine samples were thawed overnight at room temperature. Two aliquots $(2 \mathrm{ml})$ of each

220 sample were transferred to $10 \mathrm{ml}$ test tubes and $4 \mathrm{ml} 0.1 \%$ aqueous ammonia solution was

221 added. The $\mathrm{pH}$ of the extract was checked with a $\mathrm{pH}$-stick and adjusted to $\mathrm{pH} 10-11$ if

222 necessary. Following addition of heliotrine $\left(50 \mu \mathrm{l}\right.$ of a $1 \mu \mathrm{g} \mathrm{ml}^{-1}$ solution in methanol), the

223 extracts were shaken manually and purified by solid phase extraction (SPE) over Strata-X 60

$224 \mathrm{mg}, 3 \mathrm{cc}$ cartridges (Phenomenex, Torrance, CA, USA). Cartridges were conditioned with 3

$225 \mathrm{ml}$ methanol and equilibrated with $3 \mathrm{ml}$ water. After application of the sample extracts, the

226 cartridges were washed with $3 \mathrm{ml} \mathrm{1 \%}$ aqueous formic acid solution, followed by $3 \mathrm{ml} 1 \%$

227 aqueous ammonia solution. The cartridges were dried under reduced pressure and eluted with

$2283 \mathrm{ml}$ methanol. The eluates were evaporated to dryness under a gentle stream of nitrogen at

$22950^{\circ} \mathrm{C}$ and the dry residues were reconstituted in $1 \mathrm{ml}$ water/methanol 9:1 (v/v). Subsequently,

$23010 \mu 1$ was injected on the LC-M/MS system. Quantification was performed with internal

231 standard correction against a six-point matrix matched calibration curve of PA standards (0-

$232250 \mathrm{ng} \mathrm{ml}^{-1}$ ) in blank urine. For each cow individual calibration curves were constructed 
233 using a urine sample from week 1 (pre-administration period). LOQs ranged between 0.2 and $2340.5 \mu \mathrm{g} \mathrm{l}^{-1}$ for most PAs. In general, the free bases were somewhat more sensitive than the N235 oxides.

236 Deconjugation of urine samples was carried out as follows: two aliquots ( $2 \mathrm{ml})$ of the 237 urine sample were transferred to $10 \mathrm{ml}$ test tubes. The $\mathrm{pH}$ of the urine was adjusted to 4.8 238 with concentrated acetic acid. Helix pomatia extract (20 $\mu$ l) (Merck, Darmstadt, Germany) 239 was added and the sample extracts were incubated for $16 \mathrm{~h}$ at $37^{\circ} \mathrm{C}$ in a water bath. The 240 extracts were processed as described above. For each cow an individual matrix matched 241 calibration curve was included in the same concentration range as for the non-hydrolysed 242 samples. The matrix matched standards were subjected to the deconjugation procedure. 243 Faeces samples were thawed overnight at room temperature. Samples were homogenized 244 by hand with a spoon. Two aliquots $(2 \mathrm{~g})$ were transferred to $50 \mathrm{ml}$ test tubes. To the test 245 samples $40 \mathrm{ml} 2 \%$ aqueous acetic acid was added together with heliotrine $(50 \mu \mathrm{lof}$ a $1 \mu \mathrm{g} \mathrm{ml}$

$246{ }^{1}$ solution in methanol). The mixtures were extracted by rotary tumbling for $1 \mathrm{~h}$ and 247 subsequently centrifuged at $3500 \mathrm{rpm}$ for $10 \mathrm{~min}$. Twenty $\mathrm{ml}$ of the supernatant was 248 transferred to a $50 \mathrm{ml}$ test tube and the $\mathrm{pH}$ was raised to $10-11$ with concentrated ammonia.

249 The extracts were purified by SPE as described above for the urine samples. The final extracts 250 were prepared in $500 \mu \mathrm{l}$ water/methanol 9:1 (v/v). Quantification was performed with internal 251 standard correction against a six-point matrix matched calibration curve of PA standards (0$25225 \mathrm{ng} \mathrm{ml}^{-1}$ ) in blank faeces. For each cow individual calibration curves were constructed using 253 a faeces sample from week 1 (pre-administration period). LOQs were comparable to those in 254 urine. 255 256 Instrumentation 
257 Two analytical methods were developed and validated independently from each other at two 258 laboratories (RIKILT and RIVM). The two different LC-MS/MS gradients used in this study 259 were an acidic gradient for the analysis of the milk samples and an alkaline gradient for the 260 plant, urine and faeces samples. However, performance of both methods was comparable. The $261 \mathrm{pH}$ of the mobile phase has a pronounced effect on the elution of the PAs, most notably the 262 N-oxides. These elute a couple of minutes before the free bases under alkaline conditions and 263 elute just after the free bases under acidic conditions. The elution order of the specific PAs is 264 not affected by the $\mathrm{pH}$ of the mobile phase.

265 Analyses of plant extracts, urine and faeces samples for PA content were performed on a 266 Waters Acquity UPLC coupled to a Waters Quattro Premier XE tandem mass spectrometer 267 (Waters, Milford, MA, USA), operated in positive electrospray mode. The compounds were 268 separated on a Waters UPLC BEH C18 $150 \times 2.1 \mathrm{~mm}, 1.7 \mu \mathrm{m}$ analytical column, kept at $26950^{\circ} \mathrm{C}$ and run at $0.4 \mathrm{ml} \mathrm{min}^{-1}$ with an acetonitrile/water gradient containing $6.5 \mathrm{mM}$ 270 ammonia. The gradient started at $100 \%$ water and was changed to $50 \%$ acetonitrile in $12 \mathrm{~min}$. 271 Total runtime of the method was $15 \mathrm{~min}$.

272 Analysis of milk samples was performed on a Waters Acquity UPLC coupled to a Waters 273 Quattro Ultima Pt tandem mass spectrometer (Waters, Milford, MA, USA). Compounds were 274 separated on a Waters UPLC BEH C18 $100 \times 2.1 \mathrm{~mm} 1.7 \mu \mathrm{m}$ analytical column, kept at $50^{\circ} \mathrm{C}$ 275 and run at $0.35 \mathrm{ml} \mathrm{min}{ }^{-1}$ with a gradient of acetonitrile and water containing $0.1 \%$ acetic acid. 276 The gradient started at $100 \%$ water and was changed to $15 \%$ acetonitrile in $18 \mathrm{~min}$. The 277 column was washed with $80 \%$ acetonitrile for 3 min to remove slow eluting lipids. Total run 278 time was $25 \mathrm{~min}$.

279 For both systems the MS/MS collision energy was optimized for each individual 280 compound using reference standards or plant extracts when standards were not available. Two 281 precursor product ion transitions were selected and incorporated in a multiple reaction 
282 monitoring (MRM) method. The dwell time for each transition was set at $20 \mathrm{msec}$ (Premier $283 \mathrm{XE}$ ) or at $30 \mathrm{msec}$ (Ultima Pt). A total of 49 transitions was monitored in a single run to 284 include all potentially relevant PAs. In Table 1 an overview is presented of the mass 285 spectrometric settings used for the detection of the relevant PAs. All compounds could be 286 unequivocally characterized on the basis of retention time and fragmentation transitions. With 287 the final method approximately 50 compounds (including 10 metabolites) were monitored. 288 For those compounds for which no reference standard was available, a semi-quantitative 289 (indicative) value could be obtained by comparison with a closely related analogue (often an 290 isomer), which exhibited a similar MS/MS fragmentation spectrum. In these cases the same 291 transitions were used. For some compounds (e.g. jaconine and its N-oxide) no closely related 292 standard with similar MS/MS spectrum could be identified. In such cases the concentration 293 was estimated by taking the sum of the two most intense fragments and comparing this with 294 the sum area of the transitions selected for the most closely related standard (e.g. jacobine and 295 its N-oxide).

296

\section{Data modelling}

298 Transfer modelling consisted of regression analysis of the PA concentration in evening milk 299 during the exposure weeks 1, 2, 3 and 4 against the PA amount which has been administered 300 as a single bolus dose in the rumen, i.e. the amount administered with 25,50 or $100 \mathrm{~g}$ of the 301 ragwort material. In this analysis the PA concentrations during each of the exposure weeks 302 were averaged for each of the three individual animals (the PA concentrations were in fact 303 considered constant during each exposure week). These averages + SD were then used as the 304 data point in the regression analysis which resulted in a single coefficient characterising the 305 transfer from feed to milk. Next to this coefficient the percentages of the total doses which 306 were administered during one week transferred to milk were calculated. 
The milk elimination half-life of jacoline, jacobine, jaconine, senkirkine, otosenine and 308 florosenine was determined using the evening milk concentrations on day 7 of the highest 309 dose administered and day 1 to 7 of week 5 (no administration of ragwort material). On day 1 310 of week 5 also concentrations in morning milk were available and used in the calculation of 311 the milk elimination half-life. A mono-exponential pharmacokinetic approach (decay to 312 background concentration) was used to determine the milk elimination half-life:

$$
C(t)=B g+C_{1} \cdot \exp \left(-k_{1} \cdot t\right)
$$

$C$ is the concentration of PAs in milk, $C_{l}$ is model parameter for concentration level, $k_{l}$ is a 317 concentration decay rate and $B g$ is the supposed background level. The model parameters 318 were fitted to the data with a relative error data model (an absolute error data model leading to 319 a less optimal description of the data).

322 Results and Discussion

\section{Animal status}

325 Three cows were fed with 0, 50, 100, 200 and again $0 \mathrm{~g}$ of dried plant material daily, each

326 time for a period of 7 days and divided over two daily doses. The animals were exposed to

327 relatively low doses, not only to mimic a realistic situation, but also to prevent an intoxication

328 of the animals. The total dose $(2.5 \mathrm{~kg})$ given to the animals was estimated to be less than $10 \%$

329 of the lethal dose (CliniTox, 2009). The health of the animals was carefully monitored during

330 the duration of the experiment. 
Milk samples taken 3 days after changing the dosage were examined for protein, fat and

332 lactose. There were no effects of the treatment on these parameters. Protein content e.g. was

$3333.1 \pm 0.2 \%$ during the first week without ragwort, and $3.0 \pm 0.3,3.3 \pm 0.4,3.3 \pm 0.3$ and $3.1 \pm$

3340.2 during the daily treatment with 50, 100, 200 and again $0 \mathrm{~g}$ ragwort. However, no decline

335 in milk production or any signs of intoxication were observed. Figure 2 shows the milk

336 production of the three cows during the entire study. One cow (\#2) showed an indigestion at

337 the end of the fourth week, being the end of the period on the highest PA-dose. This

338 immediately affected the milk yield. Furthermore, another cow (\#1) showed mastitis at the

339 end of the second week. In both cases treatment with standard medication was successful and

340 the animals quickly recovered. However, both events are not uncommon for dairy cattle and

341 were very likely not related to the administration of ragwort.

342 The absence of an effect on the milk production clearly distinguishes our study from that 343 of Dickinson et al. (1976) in which a rapid decline in milk production was observed, possibly

344 affecting the excretion of PAs in the milk.

$346 \quad$ PA levels and composition in ragwort

347 The plant material used in this study consisted primarily (84\%) of ragwort (Senecio

348 jacobeae). Analysis of individual samples of ragwort showed minor differences between the

349 locations. The ragwort consisted primarily of jacobine, jaconine, erucifoline, senecionine and

350 seneciphylline and their corresponding N-oxides. The remainder (16\%) was dried narrow-

351 leaved ragwort (Senecio inaequidens). Major alkaloids in this plant were retrorsine,

352 senecivernine and their N-oxides. Narrow-leaved ragwort also contained small amounts of 353 otonecine-type PAs, such as senkirkine, otosenine and florosenine.

354 The homogeneity of the dried and mixed plant material was assessed by ANOVA (Fearn 355 and Thompson 2001) and was found sufficient. Table 2 shows the concentrations of the 
356 various PAs and their N-oxides in the final material. Figure 3A shows the pattern of PAs in 357 this material. The total concentration of PAs was $2.3 \mathrm{~g} \mathrm{~kg}^{-1}$ on a dry weight basis, with $82 \%$ 358 of the PAs in the N-oxide form and $18 \%$ as free bases. Jacobine and jaconine contributed 359 relatively strongly to the overall free base content, in accordance with Joosten et al. (2010). 360 Jacoline and its N-oxide contributed respectively 1.0 and $0.7 \%$ to the overall PA content. 361 Based on the overall content, during the 5 different weeks, the cows were exposed to 0,115 , 362 230, 460 and $0 \mathrm{mg}$ PAs per day respectively, divided over two dosages per day.

\section{PA concentrations in milk}

365 Analysis of milk samples revealed the presence of several tertiary bases but no N-oxides. 366 Jacoline, jacobine, jaconine, senkirkine, otosenine and florosenine were the PAs found at 367 concentrations above the limit of quantification (LOQ). Table 2 includes the average 368 concentrations for these PAs in the milk of the three cows during the period of the $200 \mathrm{~g} \mathrm{day}^{-1}$

369 dose. The pattern in milk is shown in Figure 3B. When compared with the ragwort mixture 370 (Figure 3A), a relatively high contribution of jacoline $(80.1 \pm 2.9 \%$ of the total PA content; 371 mean \pm SD for the 3 cows during the highest dosage) was observed. In the ragwort mixture, 372 the amount of jacoline free base was only $1 \%$ of the analysed PAs. Jaconine was the second 373 most important PA in milk contributing $9.4 \pm 2.9 \%$, which is more in line with the content in 374 the plant material $(5.1 \%)$. Senkirkine, otosenine and florosenine together contributed for $7.4 \pm$ $3751.5 \%$ to the PA content in milk. This is a relatively large contribution, considering the 376 approximate $1 \%$ contribution in the plant material.

377 Figure 4A shows the concentration of jacoline in the milk of the three cows during the 378 different treatment periods. Levels increased rapidly following the change to a higher dosage. 379 There were some temporary declines in the concentrations which for cow 2 coincided with the 380 indigestion (Figure 2). For the other two cows there was no explanation. Average total PA 
381 levels during the 3 different dosage periods were $2.1,5.5$ and $9.7 \mathrm{ng} \mathrm{ml}^{-1}$. When the highest 382 total PA levels, obtained at the $200 \mathrm{~g} \mathrm{day}^{-1}$ treatment, are set at $100 \%$, the average level in the 38350 and $100 \mathrm{~g} \mathrm{day}^{-1}$ period were 26 and 55\% respectively, in line with the dosage. For jacoline 384 these figures were 22, 58 and $100 \%$. Following termination of the treatment, total PA 385 concentrations rapidly declined to about $30 \%$ at the end of the first and $2 \%$ at the end of the 386 second day.

387 To check for a potential difference in the PA content of the morning and evening milk 388 samples, morning milk samples of the $4^{\text {th }}$ week, i.e. the period with the highest dosage, were 389 also analysed. The average concentrations are presented in Figure 4B. The small but 390 consistent differences found between morning (M) and evening milk (E) probably reflect the 391 differences in time between dosage and milking (10 $\mathrm{h}$ for the evening milk and $14 \mathrm{~h}$ for the 392 morning milk with $54 \%$ of the daily milk production in the morning milk), and suggest that 393 the majority of transfer of the PAs to milk occurs in the first hours after dosing, after which 394 dilution occurs with more milk being produced. Similar patterns have been found for lactose, 395 fat and protein content of morning and evening milk (Meijer, personal comment).

396 Based on the milk production of about 40 litres per day and a total PA concentration of 10 $397 \mu \mathrm{g} \mathrm{l}^{-1}$ during the highest dosage level, the overall amount excreted in the milk was $400 \mu \mathrm{g}$ 398 PAs day ${ }^{-1}$ or about $0.1 \%$ of the overall daily dose of PAs (N-oxides + free bases). This figure 399 is similar to that calculated from the study of Dickinson et al. (1976) but that study only 400 included the free bases. When compared to only the free-base PAs in the ragwort (18\% of 401 total), the overall transfer was $0.5 \%$. Regarding jacoline, about $4 \%$ of this PA and its N-oxide 402 present in the plant material ended up in the milk as the free base, or $7 \%$ when only jacoline 403 as free base is considered. Panariti et al. (1997) dosed sheep for 5 days with about $30 \mathrm{mg}$ 404 radiolabelled seneciphylline per day and observed milk levels up to $1 \mathrm{mg}^{\mathrm{l}^{-1}}$. This would 405 correspond to a transfer rate of $3 \%$, being much higher than observed in our study for this 
406 compound. However, the levels were based solely on the radiolabel and may as well represent 407 metabolites including macromolecular adducts. Candrian et al. (1991) treated one lactating 408 cow with a single dose of $547 \mathrm{mg}$ radiolabelled seneciphylline and observed milk levels 409 corresponding up to $0.1 \mathrm{mg} \mathrm{l}^{-1}$. The overall amount of radiolabel detected in the milk was $4100.16 \%$. However, only part of this appeared to correspond to the free base and some N-oxide. 411 Our study did show traces of hydroxylated metabolites in milk (data not shown). However, no 412 detectable amounts of seneciphylline and its N-oxide were found in milk.

\section{$P A$ concentrations in urine and faeces}

415 Urine and faeces samples were collected on two days during each week at the end of the 416 morning, about 4-6 hours after the dosing of the ragwort. Samples were taken directly from 417 the cows. Table 3 shows the total PA concentrations in urine for the three cows. There was a 418 more or less dose-related increase in the concentrations, average levels in the five different 419 weeks being $0,107,201,398$ and $3 \mu \mathrm{g} \mathrm{l}^{-1}$. In the last week, the samples were taken 2 and 6 420 days after the last treatment, the samples from day 2 after treatment still showing slightly 421 elevated levels. Most PAs present in the plant material could also be detected in the urine 422 (Table 2). Application of a glucuronide/sulfate deconjugation step in the analysis resulted in a 423 slightly (14\%) elevated total concentration. This was primarily due to seneciphylline and 424 erucifoline. Apparently, these PAs are excreted in urine mainly as conjugates, most likely as 425 glucuronides. The concentrations of most other PAs were not affected by the deconjugation 426 step, indicating that these PAs are present primarily in a non-conjugated form. This is clearly 427 demonstrated in Figure 3C, showing the patterns of the urine samples taken during the week 428 on the highest dosage, both before and after deconjugation. Compared to the composition of 429 the original plant material, it is clear that the pattern in urine is rather different. Jacobine-N430 oxide was by far the most important PA in urine (38.4 $\pm 4.8 \%$; mean \pm SD for the 3 cows) 
431 whereas in the plant material it contributed for only $14 \%$. On the other hand, the N-oxides of 432 erucifoline, retrorsine and senecionine, contributing for respectively 21,14 and $11 \%$ in the 433 plants, made up only $3.9 \pm 1.5,5.3 \pm 2.6$ and $1.2 \pm 0.1 \%$ in the urine. Jacoline, a minor PA in 434 ragwort (1\%) but by far the most important PA in milk, contributed for $14.1 \pm 2.1 \%$ in the 435 urine. Also the otonecine PAs are relatively abundant in urine, contributing for $8.5 \%$ as 436 compared to $1 \%$ in the ragwort material. The change in the pattern clearly indicates that some 437 PAs are more efficiently metabolized than others. Alternatively, some PAs may be 438 transformed into other ones as recently found in a study on the metabolism of adonifoline (the 439 major PA in a related ragwort species, Senecio scandens) in the rat (Xiong et al. 2009b). In 440 this study it was shown that adonifoline was metabolised to a number of hydroxylated 441 metabolites and (dehydro)retronecine derivatives. Very recently, glucuronidation by liver 442 microsomes was reported as a new metabolic pathway for PAs (He et al. 2010). In our 443 chromatograms of urine samples several new peaks were present that likely represent 444 hydroxylated metabolites of PAs (free bases and N-oxides) occurring in ragwort. Up to 10 445 new compounds with masses $350,352,366,368$ and 370 were detected, that were not present 446 in the plant material or in the urine samples before the treatment. The most important 447 metabolites are hydroxy-senecionine and hydroxy-integerrimine and their corresponding N448 oxides. Accurate quantification was difficult, due to the absence of reference standards, but it 449 was estimated that between 15 to $25 \%$ of the excreted PAs in urine were newly formed 450 compounds not present in ragwort. No efforts were undertaken to detect metabolites with a 451 dehydroretronecine moiety or related conjugates.

452 Since the urine was not collected quantitatively, it is difficult to determine the overall 453 fraction of ingested PAs that was accounted for in the urine. When assuming a total urine 454 production of 40 litres per day, roughly $17 \mathrm{mg}$ of PAs would be excreted in the urine during 455 the period on the highest dosage, as compared to an intake of about $450 \mathrm{mg}$ per day. The 
456 identified hydroxy-metabolites would add an estimated $4 \mathrm{mg}$ to this amount. The time lag 457 between the dosing and the time of sampling of the urine is approximately 4-6 hours (morning 458 dosing) and 18-20 $\mathrm{h}$ (evening dosing). It is however unlikely that the total amount excreted in 459 urine will be very much higher than estimated on the basis of the $4-6 \mathrm{~h}$ sample. This can be 460 derived from the concentrations of jacoline and the otonecine PAs senkirkine, otosenine and 461 florosenine found in the collected urine. The average amount of jacoline detected in urine 462 accounted for approx. $60 \%$ of the jacoline present in the ragwort. Senkirkine was present at a 463 concentration which accounted for $34 \%$ of the original dose, otosenine for $37 \%$ and 464 florosenine for $33 \%$. As will be discussed below, jacoline and the otonecine PAs were also 465 present in faeces in substantial amounts. Other studies have also indicated that extensive 466 metabolism of PAs occurs and that only a minor part of the PAs is excreted unchanged in 467 urine and faeces (Estep et al. 1990; Chu and Segall 1991)

468 Total PA concentrations in faeces samples are shown in Table 3. There was more or less a 469 dose-related increase in the concentrations, on average being $0,23,38,65$ and $4 \mu \mathrm{g} \mathrm{kg}^{-1}$ in the 4705 different weeks. Table 2 shows the concentrations of the different PAs in the samples taken 471 during the week on the highest dosage. The samples contained practically no N-oxides. As in 472 the milk, jacoline was the most important PA, contributing for $36.1 \pm 7.3 \%$ to the total PA 473 content (Figure 3D). Other important PAs in faeces were jacobine (13.2 $\pm 4.6 \%)$, and the 474 otonecine PAs otosenine $(12.4 \pm 1.1 \%)$, floridanine $(12.0 \pm 2.7 \%)$ and florosenine $(8.8 \pm$ 475 2.4\%). Together, these components made up $82 \pm 2 \%$ of the PAs in faeces, as compared to 87 $476 \pm 3 \%$ in the milk, $23 \pm 3 \%$ in urine and only $5 \%$ in the original plant material. Based on $40 \mathrm{~kg}$ 477 of faeces per day, the total amount excreted in faeces was estimated to be $2.6 \mathrm{mg}$, 478 representing less than $1 \%$ of the original PAs during the highest dosage period. Nevertheless, 479 the average amount of jacoline excreted in the faeces accounted for $19 \%$ of the amount 480 present in the ragwort material, that of senkirkine for $3 \%$, otosenine for $27 \%$, florosenine for 
$48114 \%$ and floridanine for $115 \%$. Some of the metabolites found in urine were also detected in

482 faeces, albeit at relatively low concentrations. Hydroxy-senecionine and hydroxy-

483 integerrimine were two of the major metabolites also found in urine. The contribution of

484 hydroxylated PA metabolites to the total excretion in faeces was estimated to be between 5 to $48510 \%$.

486 Although it should be clear that urine and faeces samples may not have been collected at 487 the peak of the excretion, both the concentrations and the change in the patterns indicate 488 intensive metabolism. The major question is whether this could result in toxic metabolites or 489 compounds that can be transformed into toxic metabolites, knowing that the toxicity of PAs is 490 caused by reactive metabolites. If so, the major issue would be if such metabolites could 491 actually be present in the milk, and as such present a further risk to the consumer. The studies 492 with radiolabelled seneciphylline indicate that metabolites may indeed be excreted into the 493 milk (Candrian et al. 1991; Panariti et al. 1997).

494

$495 \quad$ Modelling of transfer to milk

496 As shown in Figure 4A, transfer of jacoline to milk quickly led tot a rather constant, i.e.

497 "steady state", concentration in evening milk. In this way, for each of the four dose levels 498 tested, an animal specific "steady state" concentration in milk was obtained. Analysing these 499 levels with simple regression analysis led to a transfer coefficient of $3.7 \times 10^{-3} \mu \mathrm{g}^{-1}$ per $\mu \mathrm{g}$ of 500 administered jacoline (see Figure 5A). After the exposure was stopped, jacoline rapidly 501 disappeared from the milk (and thus from the animal's body). The half-life for jacoline in 502 milk was calculated to be 8 hours (Figure 5B).

503 As with jacoline the other 5 PAs detected in milk quickly reached a "steady state" (data 504 not shown). Transfer coefficients amounted to $3 \times 10^{-5}$ (jacobine), $7 \times 10^{-5}$ (jaconine), $5 \times 10^{-4}$ 505 (senkirkine), and $2 \times 10^{-4}$ (otosenine and florosenine) $\mu \mathrm{g} \mathrm{l}^{-1}$ per $\mu \mathrm{g}$ of administered compound. 
506 Elimination half-lives from milk were 8 hours (jacobine), 6 hours (jaconine), 16 hours 507 (senkirkine) and 9 hours (otosenine and florosenine).

508

\section{Relevance of the data for other plant species}

510 The rather selective carry-over of jacoline, jaconine and some of the otonecines suggests that

511 not all PAs and as such PA-containing plants may be of equal potential relevance for

512 consumers of milk from exposed animals. It also raises the question which properties are

513 relevant for possible transfer to milk. It seems obvious that the potential of the animal for the

514 biotransformation of individual compounds plays an essential role. The N-oxides, which were

515 prominent compounds in the ragwort material, were not detected in milk and faeces samples.

516 In urine $\mathrm{N}$-oxides were present, accounting for $56 \%$ of the excreted PAs. Of the N-oxides

517 excreted jacobine-N-oxide was predominant whereas those of other PAs were almost or

518 completely absent. This indicates that either intensive metabolism or very rapid excretion via

519 urine (depletion in less than $4 \mathrm{~h}$ ) takes place. However, preliminary studies with liver slices

520 from cows did not show significant degradation of these N-oxides. Similar was true for

521 jacoline whereas other free bases like senecionine, seneciphylline, erucifoline and jacobine

522 were substantially metabolized. In this study there were no indications for the transformation

523 of certain PAs into their N-oxides or into other PAs. Jacoline was the major or second

524 metabolite present in milk, urine and faeces. Assuming that jacoline is not formed by

525 metabolism from other PAs, around $85 \%$ of the free jacoline present in the ragwort material

526 was accounted for in milk, urine and faeces. Taking jacoline and its N-oxide together, still

$52750 \%$ could be found in these matrices. The otonecine PAs seem to be relatively stable as well.

528 Excretion percentages for these PAs vary from 35\% (senkirkine) to over 110\% (floridanine).

529 The potential role of the bacteria and other micro-organisms in the rumen or intestines

530 should not be ignored (Mattocks 1971; Aguiar and Wink 2005). Lanigan (1970) showed that 
531 the N-oxide of heliotrine was effectively metabolized by ovine ruminal fluid to the free base

532 and subsequently l-goreensine and 7-hydroxy-1-methylpyrrolizidin. The possibility that e.g.

533 jacoline may also have been formed from other PAs is important when focussing on plants

534 containing PAs that are transferred to milk. Furthermore it should be mentioned that the

535 majority (82\%) of the PAs in the ragwort material used was in the N-oxide form. In the

536 studies of Dickinson et al. (1976) and Deinzer et al. (1982) the ragwort material was not

537 analysed for N-oxide content, but it is reasonable to assume that this was not very different

538 from our study. However, upon storage and depending on the drying conditions, the relative

539 contribution of the free bases may become more prominent. Recent screening of animal

540 forages in The Netherlands seem to corroborate this: often the amount of free bases was

541 higher than that of the N-oxides (Mulder et al. 2010). Consequently, a high content of free PA

542 bases in a specific animal feed could lead to a relatively high transfer of PAs to milk.

\section{Conclusions}

545 The present study investigated the potential carry-over of PAs present in ragwort and narrow-

546 leaved ragwort to milk. The amount of ragwort given to the cows had no immediate effects on

547 the milk production. The carry-over to milk in our study resembled that in the study by

548 Dickinson et al. (1976), notwithstanding that in our study the ragwort dosages were 20 to 100

549 times lower. Similar to the study of Dickinson, the overall transfer of PAs was rather low

$550(0.1 \%)$, but this figure may be higher for specific PAs, like jacoline (4-7\% depending on

551 whether or not the $\mathrm{N}$-oxide is taken into account as a precursor) and the otonecine type PAs.

552 Furthermore, there are strong indications for substantial metabolism of the PAs in cows,

553 raising attention to the possible transfer of metabolites into the milk. At the highest dosage

554 level of $200 \mathrm{~g}$ dried ragwort per day, the VSD in consumers would be reached at a daily

555 intake of 2-10 $\mathrm{ml}$ of affected milk. This urges for more research towards the risk of specific 
1

3

4

5

6

7

8

9

10

556 PAs, like jacoline, in milk but also in other food items. Since PAs can be classified as

557 genotoxic carcinogens and since metabolites are known to be involved in these effects, further

558 studies are needed to investigate the potential risks of ingestion of PA-containing herbs by

559 food-producing animals and the risk of milk consumption in specific situations.

560

561 Acknowledgements

562 The authors would like to thank Cynthia Koot and Bart Hoogenboom for their contribution to

563 the collection and preparation of the ragwort material. We also would like to thank Jan van

564 Eijkeren for modelling the transfer to milk and calculation of the half-life. The study was

565 financed by the Dutch Ministry of Agriculture, Nature and Food Quality and by the Dutch

566 Food and Consumer Product Safety Authority (VWA).

567 


\section{References}

569 Aguiar R, Wink M. 2005. Do naïve ruminants degrade alkaloids in the rumen? J Chem Ecol. $570 \quad 31: 761-787$.

571 Boppré M, Colegate SM, Edgar JA, Fischer OW. 2008. Hepatotoxic pyrrolizidine alkaloids in 572 pollen and drying-related implications for commercial processing of bee pollen. J Agric $573 \quad$ Food Chem. 56: 5662-5672.

574 Bull LB, Culvenor CCJ, Dick AT. 1968. The pyrrolizidine alkaloids, in Frontiers of Biology 575 (Eds. Neuberger A, Tatum EL), Amsterdam, North-Holland Publishing.

576 Candrian U, Zweifel U, Lüthy J, Schlatter C. 1991. Transfer of orally administered $577 \quad\left[{ }^{3} \mathrm{H}\right]$ Seneciphylline into cow's milk. J Agric Food Chem. 39: 930-933. 578 CliniTox Giftpflanzen. 2009, www.vetpharm.uzh.ch/giftdb/pflanzen/0038_vet.htm, assessed $579 \quad$ Feb 10, 2010.

580 Chou MW, Wang YP, Yan J, Yang YC, Beger RD, Williams LD, Doerge DR, Fu PP. 2003. 581 Riddelliine N-oxide is a phytochemical and mammalian metabolite with genotoxic 582 activity that is comparable to the parent pyrrolizidine alkaloid riddelliine. Toxicology $583 \quad$ Letters. 145: 239-247.

584 Chu PS, Segall HJ. 1991. Species difference in the urinary excretion of isatinecic acid from 585 the pyrrolizidine alkaloid retrorsine. Comp Biochem Physiol. 100C: 683-686.

586 Crews C, Berthiller F, Krska R. 2010. Update on analytical methods for toxic pyrrolizidine $587 \quad$ alkaloids. Anal Bioanal Chem. 396: 327-338.

588 Crews C, Startin JR, Clarke PA. 1997. Determination of pyrrolizidine alkaloids in honey from 589 selected sites by solid phase extraction and HPLC-MS. Food Add Contam. 14: 419-428.

590 Deinzer ML, Arbogast BL, Buhler DR, Cheeke PR. 1982. Gas Chromatographic 591 determination of pyrrolizidine alkaloids in goat's milk. Anal Chem. 54: 1811-1814. 
592 Dickinson JO, Cooke MP, King RR, and Mohamed PA. 1976. Milk transfer of pyrrolizidine 593 alkaloids in cattle. J Am Vet Med Assoc. 169: 1192-1196.

594 Edgar JA, Roeder E, Molyneux RJ. 2002. Honey from plants containing pyrrolizidine 595 alkaloids: A potential threat to health. J Agric Food Chem. 50: 2719-2730.

596 EFSA. 2007. Opinion of the Scientific panel on contaminants in the food chain on a request 597 from the European Commission related to pyrrolizidine alkaloids as undesirable $598 \quad$ substances in animal feed. The EFSA J. 447: 1-51.

599 Estep JE, Lamé MW, Segall HJ. 1990. Excretion and blood radioactivity levels following $600 \quad\left[{ }^{14} \mathrm{C}\right]$ senecionine administration in the rat. Toxicology. 64: 179-189.

601 Fu PP, Xia Q, Lin G, Chou MW. 2004. Pyrrolizidine alkaloids - genotoxicity, metabolism, 602 enzymes, metabolic activation, and mechanisms. Drug Metabolism Reviews 36: 1-55. 603 Fearn T, Thompson M. 2001. A new test for 'sufficient homogeneity'. Analyst. 126: 1414$604 \quad 1417$.

605 Hartmann T, Witte, L. Chemistry, Biology and chemoecology of the pyrrolizidine alkaloids. 606 1995. In Chemical and Biological Perspectives, Pelletier SW, editor, vol 9, Pergamon $607 \quad$ Press, Oxford, pp 155-233.

608 Hartmann T, Toppel G. 1986. Senecionine N-oxide, the primary product of pyrrolizidine 609 alkaloid biosynthesis in root cultures of Senecio vulgaris. Phytochemistry. 26: 1639-1643. 610 He YQ, Yang L, Liu HX, Zhang JW, Liu Y, Fong A, Xiong AZ, Lu YL, Yang L, Wang, CH, 611 Wang ZT. 2010. Glucuronidation, a new metabolic pathway for pyrrolizidine alkaloids. $612 \quad$ Chem Res Toxicol. 23: 591-599.

613 Joosten L, Mulder PPJ, Klinkhamer PGL, Veen JA van. 2009. Soil-borne microorganisms and 614 soil-type affect pyrrolizidine alkaloids in Jacobaea vulgaris. Plant Soil. 325: 133-143. 
615 Joosten L, Mulder PPJ, Vrieling K, Veen JA van, Klinkhamer PGL. 2010. The analysis of 616 pyrrolizidine alkaloids in Jacobaea vulgaris; a comparison of extraction and detection 617 methods. Phytochem Anal. 21: 197-204.

618 Lanigan GW. 1970. Metabolism of pyrrolizidine alkaloids in ovine rumen.2. some factors 619 affecting rate of alkaloid breakdown by rumen fluid in-vitro. Aust J Agric Res. 21: 633$620 \quad 639$.

621 Lindigkeit R, Biller A, Buch M, Schiebel H.M, Boppré M, Hartmann T. 1997. The two faces 622 of pyrrolizidine alkaloids: the role of the tertiary amine and its N-oxide in chemical 623 defense of insect with acquired plant toxins. Eur J Biochem. 245: 626-636.

624 Mattocks AR. 1971. Hepatotoxic effects due to pyrrolizidine alkaloid N-oxides. Xenobiotica. $625 \quad 1: 563-565$.

626 Molyneux RJ, James LF. 1990. Pyrrolizidine alkaloids in milk: thresholds of intoxication. Vet 627 Hum Toxicol. 32: 94-103.

628 Mulder PPJ, Beumer B, Oosterink E, de Jong J. 2010. Dutch survey on pyrrolizidine alkaloids 629 in animal forage. RIKILT report 2009.518. Available on the WUR website. 630 http://edepot.wur.nl/135952.

631 Oosterink E, Mulder PPJ. 2008. Standard operation procedure RSV A1070 Grass forage 632 confirmation of pyrrolizidine alkaloids by LC-MS/MS (in Dutch), RIKILT, Wageningen, 633 The Netherlands.

634 Panariti E, Xinxo A, Leksani D. 1997, Transfer of ${ }^{14}$ C-seneciphylline into sheep milk 635 following multiple oral intakes. Deutsche Tierärtzl Wochenschr 104: 85-124.

636 Top H van den, Schothorst R. 2007. Standard operation procedure for the determination of 637 pyrrolizidine alkaloids in milk by LC-MS/MS, ARO/527 (in Dutch), RIVM-ARO, 638 Bilthoven, The Netherlands. 
639 Xiong A, Li Y, Yang L, Gao J, He Y, Wang C, Wang Z. 2009a. Simultaneous determination 640 of sencionine, adonifoline and their metabolites in rat serum by UPLC-ESIMS and its 641 application in pharmacokinetic studies. J Pharm Biomed Anal. 50: 1070-1074.

642 Xiong A. Yang L, He Y, Zhang F, Wang J, Han H, Wang C, Bligh SWA, Wang Z. 2009b. 643 Identification of metabolites of adonifoline, a hepatotoxic pyrrolizidine alkaloid, by liquid 644 chromatography/tandem and high-resolution mass spectrometry. Rapid Commun Mass $645 \quad$ Spectrom. 23: 3907-3916.

646 Zee, M van der. 2005. Advies inzake pyrrolyzidine alkaloïden in kruidenpreparaten, 647 FO advies dd. 27-04-2005, Centrum voor Stoffen en Integrale Risicoschatting, RIVM, 648 Bilthoven. 


\section{$649 \quad$ Legends}

650

651 Figure 1. Chemical structures of pyrrolizidine alkaloids representative for ragwort species. 652

653 Figure 2. Milk production of the three cows during administration of 0 (day 1-7), 50 (day 8-

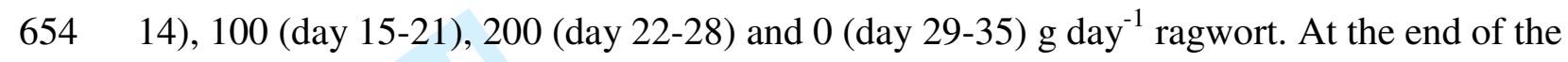
655 fourth week cow 2 showed indigestion.

656

657 Figure 3. Pattern of PAs in the ragwort used for the study (A), and milk (B), urine (C) and 658 faeces (D) collected during the period on the highest ragwort level. In the case of urine the 659 pattern includes both PA concentrations obtained both without (light) and with a 660 deconjugation step (dark). Abbreviations of the different PAs are listed in Table 1. 661

662 Figure 4. Concentrations $\left(\mu \mathrm{g}^{-1}\right)$ of jacoline in evening milk of the 3 cows dosed with 0 (day 663 1-7), 50 (day 8-14), 100 (day 15-21), 200 (day 22-28) or 0 (day 29-35) $\mathrm{g} \mathrm{day}^{-1}$ of ragwort (A). 664 Solid lines represent the average steady state levels for jacoline in each period. Figure B 665 shows concentrations of total PAs $\left(\mu \mathrm{g} \mathrm{l}^{-1}\right)$ in morning $(\mathrm{M})$ and evening $(\mathrm{E})$ milk starting with 666 the morning milk samples just before the first dose of $100 \mathrm{~g}$ of plant material and ending with 667 the evening milk taken 24 hours after the last dosing. Concentrations are the average of the 3 668 cows \pm SD.

669

670 Figure 5 Transfer model of jacoline from Senecio from feed to milk (A, weekly mean \pm SD of 671 the milk concentration of each individual cow: solid line $\left(y=3.7 \times 10^{-3} x+0.0721\right)$ and the 672 half-life in milk after exposure had stopped (B).

673 
Table 1. MS/MS conditions used for the analysis of pyrrolizidine alkaloids. The standard that has been used for quantification of the individual compounds is indicated.

\begin{tabular}{|c|c|c|c|c|c|}
\hline Compound & Abbreviation & $\begin{array}{l}\text { Precursor } \\
\text { ion }(\mathrm{m} / \mathrm{z})\end{array}$ & $\begin{array}{l}\text { Product ions } \\
\qquad(\mathrm{m} / \mathrm{z})\end{array}$ & $\begin{array}{c}\text { Collision } \\
\text { energy } \\
(\mathrm{eV})\end{array}$ & $\begin{array}{l}\text { Standard used } \\
\text { for } \\
\text { quantification }\end{array}$ \\
\hline Heliotrine (IS) & Hel & 314.2 & 138.0 & 25 & \\
\hline Senecionine & $\mathrm{Sn}$ & 336.2 & $94.0 ; 120.0$ & $40 ; 30$ & $\mathrm{Sn}$ \\
\hline Senecionine $\mathrm{N}$-oxide & Sn-ox & 352.2 & $94.0 ; 120.0$ & $40 ; 30$ & Sn-ox \\
\hline Integerrimine & Ir & 336.2 & $94.0 ; 120.0$ & $40 ; 30$ & Ir \\
\hline Integerrimine $\mathrm{N}$-oxide & Ir-ox & 352.2 & $94.0 ; 120.0$ & $40 ; 30$ & Ir-ox \\
\hline Senecivernine & $\mathrm{Sv}$ & 336.2 & $94.0 ; 120.0$ & $40 ; 30$ & Ir \\
\hline Senecivernine $\mathrm{N}$-oxide & Sv-ox & 352.2 & $94.0 ; 120.0$ & $40 ; 30$ & Ir-ox \\
\hline Retrorsine & Rt & 352.2 & $94.0 ; 120.0$ & $40 ; 30$ & Rt \\
\hline Retrorsine $\mathrm{N}$-oxide & Rt-ox & 368.2 & $94.0 ; 120.0$ & $40 ; 30$ & Rt-ox \\
\hline Usaramine & Us & 352.2 & $94.0 ; 120.0$ & $40 ; 30$ & Rt \\
\hline Usaramine $\mathrm{N}$-oxide & Us-ox & 368.2 & $94.0 ; 120.0$ & $40 ; 30$ & Rt-ox \\
\hline Riddelliine & $\mathrm{Rd}$ & 350.2 & $94.0 ; 138.0$ & $40 ; 30$ & $\mathrm{Rd}$ \\
\hline Riddelliine N-oxide & Rd-ox & 366.2 & $94.0 ; 118.0$ & $40 ; 30$ & Rd-ox \\
\hline Seneciphylline & $\mathrm{Sp}$ & 334.2 & $94.0 ; 120.0$ & $40 ; 30$ & $\mathrm{Sp}$ \\
\hline Seneciphylline N-oxide & Sp-ox & 350.2 & $94.0 ; 138.0$ & $40 ; 30$ & Sp-ox \\
\hline Spartioidine & St & 334.2 & $120.0 ; 138.0$ & $30 ; 30$ & $\mathrm{Sp}$ \\
\hline Spartioidine N-oxide & St-ox & 350.2 & $94.0 ; 138.0$ & $40 ; 30$ & Sp-ox \\
\hline Acetylseneciphylline & AcSp & 376.2 & $120.0 ; 138.0$ & $30 ; 30$ & AcSp \\
\hline Acetylseneciphylline $\mathrm{N}$-oxide & AcSp-ox & 392.2 & $94.0 ; 118.0$ & $40 ; 30$ & AcSp-ox \\
\hline Jacobine & $\mathrm{Jb}$ & 352.2 & $120.0 ; 155.0$ & $30 ; 30$ & $\mathrm{Jb}$ \\
\hline Jacobine N-oxide & Jb-ox & 368.2 & $120.0 ; 296.0$ & $30 ; 25$ & Jb-ox \\
\hline Jacoline & $\mathrm{Jl}$ & 370.2 & $94.0 ; 138.0$ & $40 ; 30$ & $\mathrm{Jl}$ \\
\hline Jacoline N-oxide & Jl-ox & 386.2 & $94.0 ; 120.0$ & $40 ; 30$ & $\mathrm{Jb}-\mathrm{ox}$ \\
\hline Jaconine & $\mathrm{Jn}$ & 388.2 & $94.0 ; 120.0$ & $40 ; 30$ & $\mathrm{Jb}$ \\
\hline Jaconine N-oxide & Jn-ox & 404.2 & $94.0 ; 138.0$ & $40 ; 30$ & $\mathrm{Jb}-\mathrm{ox}$ \\
\hline Jacozine & $\mathrm{Jz}$ & 350.2 & $94.0 ; 138.0$ & $40 ; 30$ & $\mathrm{Jb}$ \\
\hline Dehydrojaconine & DhJn & 386.2 & $94.0 ; 120.0$ & $40 ; 30$ & $\mathrm{Jb}$ \\
\hline Erucifoline & $\mathrm{Er}$ & 350.2 & $94.0 ; 120.0$ & $40 ; 30$ & $\mathrm{Er}$ \\
\hline Erucifoline $\mathrm{N}$-oxide & Er-ox & 366.2 & $94.0 ; 118.0$ & $40 ; 30$ & Er-ox \\
\hline Acetylerucifoline & AcEr & 392.2 & $94.0 ; 118.0$ & $40 ; 30$ & Er \\
\hline Acetylerucifoline $\mathrm{N}$-oxide & AcEr-ox & 408.2 & $94.0 ; 120.0$ & $40 ; 30$ & Er-ox \\
\hline Senkirkine & Sk & 366.2 & $122.0 ; 168.0$ & $30 ; 25$ & Sk \\
\hline Otosenine & Ot & 382.2 & $122.0 ; 168.0$ & $30 ; 25$ & Ot \\
\hline Onetine & On & 400.2 & $122.0 ; 168.0$ & $30 ; 30$ & Ot \\
\hline Desacetyldoronine & DesDor & 418.2 & $122.0 ; 168.0$ & $30 ; 30$ & Ot \\
\hline Florosenine & Fs & 424.2 & $122.0 ; 168.0$ & $35 ; 30$ & Fs \\
\hline Floridanine & $\mathrm{Fd}$ & 442.2 & $122.0 ; 168.0$ & $30 ; 30$ & $\mathrm{Ot}$ \\
\hline
\end{tabular}


Table 2. Concentrations of PAs in ragwort, milk, urine and faeces samples. Data on milk, urine and faeces are the averages found in the samples from the 3 cows during the period on $200 \mathrm{~g}$ plant material per day. Urine data are concentrations after deconjugation of the samples. SD represents the variation between the 3 cows. Empty cells indicate not detected.

\begin{tabular}{|c|c|c|c|c|c|}
\hline Compound & & $\begin{array}{c}\text { ragwort } \\
\left(\mathrm{mg} \mathrm{kg}^{-1} \mathrm{dw}\right)\end{array}$ & $\begin{array}{c}\text { milk } \\
\left(\mu \mathrm{g} \mathrm{l}^{-1}\right)\end{array}$ & $\begin{array}{c}\text { urine } \\
\left(\mu \mathrm{g} \mathrm{l}^{-1}\right)\end{array}$ & $\begin{array}{c}\text { faeces } \\
\left(\mu \mathrm{g} \mathrm{kg}^{-1}\right)\end{array}$ \\
\hline Senecionine & $\mathrm{Sn}$ & $24.8 \pm 1.5$ & & $1.2 \pm 0.1$ & $0.3 \pm 0.0$ \\
\hline Senecionine $\mathrm{N}$-oxide & Sn-ox & $253.0 \pm 20.3$ & & $5.3 \pm 1.7$ & $0.8 \pm 0.4$ \\
\hline Integerrimine & Ir & $8.4 \pm 0.5$ & & $0.6 \pm 0.2$ & $0.2 \pm 0.0$ \\
\hline Integerrimine $\mathrm{N}$-oxide & Ir-ox & $103.4 \pm 6.4$ & & $6.0 \pm 1.9$ & \\
\hline Senecivernine & Sv & $3.1 \pm 0.3$ & & $0.1 \pm 0.1$ & \\
\hline Senecivernine N-oxide & Sv-ox & $100.9 \pm 11.2$ & & & \\
\hline Retrorsine & Rt & $9.9 \pm 1.0$ & & $6.2 \pm 1.9$ & $1.4 \pm 0.7$ \\
\hline Retrorsine $\mathrm{N}$-oxide & Rt-ox & $336.1 \pm 30.7$ & & $22.5 \pm 11.3$ & \\
\hline Usuramine & Us & $1.7 \pm 0.3$ & & $3.4 \pm 1.6$ & \\
\hline Usuramine $\mathrm{N}$-oxide & Us-ox & $44.5 \pm 4.4$ & & $3.7 \pm 1.8$ & \\
\hline Riddelliine & $\mathrm{Rd}$ & $1.7 \pm 0.2$ & & $0.9 \pm 0.4$ & \\
\hline Riddelliine $\mathrm{N}$-oxide & Rd-ox & $22.5 \pm 1.7$ & & $1.4 \pm 0.3$ & \\
\hline Seneciphylline & $\mathrm{Sp}$ & $29.4 \pm 1.8$ & & $28.2 \pm 3.5$ & $0.9 \pm 0.1$ \\
\hline Seneciphylline N-oxide & Sp-ox & $189.4 \pm 14.3$ & & $12.7 \pm 4.6$ & \\
\hline Spartioidine & St & $1.1 \pm 0.1$ & & $0.3 \pm 0.0$ & \\
\hline Spartioidine N-oxide & St-ox & $5.7 \pm 0.5$ & & & \\
\hline Acetylseneciphylline & $\mathrm{AcSp}$ & $0.3 \pm 0.1$ & & & \\
\hline Acetylseneciphylline $\mathrm{N}$-oxide & AcSp-ox & $4.8 \pm 0.8$ & & & \\
\hline Jacobine & $\mathrm{Jb}$ & $84.7 \pm 5.5$ & $0.30 \pm 0.11$ & $17.2 \pm 5.7$ & $8.8 \pm 4.6$ \\
\hline Jacobine N-oxide & $\mathrm{Jb}-\mathrm{ox}$ & $325.4 \pm 18.3$ & & $161.6 \pm 33.2$ & $0.3 \pm 0.2$ \\
\hline Jacoline & $\mathrm{J} 1$ & $21.8 \pm 1.3$ & $7.75 \pm 0.83$ & $61.2 \pm 23.3$ & $24.2 \pm 9.6$ \\
\hline Jacoline N-oxide & Jl-ox & $17.8 \pm 1.4$ & & $5.9 \pm 1.9$ & \\
\hline Jaconine & $\mathrm{Jn}$ & $119.2 \pm 8.0$ & $0.94 \pm 0.39$ & $2.3 \pm 0.2$ & $1.6 \pm 0.7$ \\
\hline Jaconine N-oxide & Jn-ox & $5.8 \pm 0.5$ & & & \\
\hline Jacozine & $\mathrm{Jz}$ & $2.6 \pm 0.2$ & & $0.8 \pm 0.4$ & \\
\hline Dehydrojaconine & DHJn & $4.9 \pm 0.4$ & & & \\
\hline Erucifoline & $\mathrm{Er}$ & $77.0 \pm 5.1$ & & $28.5 \pm 12.0$ & $2.9 \pm 1.0$ \\
\hline Erucifoline $\mathrm{N}$-oxide & Er-ox & $481.6 \pm 29.9$ & & $17.5 \pm 10.6$ & \\
\hline Acetylerucifoline & AcEr & $1.7 \pm 0.2$ & & & \\
\hline Acetylerucifoline $\mathrm{N}$-oxide & AcEr-ox & $29.7 \pm 1.7$ & & & \\
\hline Senkirkine & Sk & $8.0 \pm 1.6$ & $0.40 \pm 0.15$ & $13.6 \pm 1.6$ & $1.2 \pm 0.4$ \\
\hline Otosenine & Ot & $5.9 \pm 0.5$ & $0.11 \pm 0.01$ & $11.1 \pm 3.4$ & $8.0 \pm 1.8$ \\
\hline Onetine & On & $1.3 \pm 0.1$ & & $0.2 \pm 0.1$ & $1.3 \pm 0.2$ \\
\hline Desacetyldoronine & Desdor & $1.1 \pm 0.2$ & & $0.2 \pm 0.0$ & $0.3 \pm 0.2$ \\
\hline Florosenine & Fs & $8.1 \pm 0.8$ & $0.21 \pm 0.02$ & $11.0 \pm 3.6$ & $5.5 \pm 0.1$ \\
\hline Floridanine & $\mathrm{Fd}$ & $1.3 \pm 0.1$ & & $0.4 \pm 0.1$ & $7.6 \pm 0.6$ \\
\hline Sum retronecine bases & & $392 \pm 20$ & $8.99 \pm 1.31$ & $150.8 \pm 38.0$ & $40.3 \pm 14.4$ \\
\hline Sum retronecine N-oxides & & $1921 \pm 102$ & & $238.0 \pm 54.3$ & $1.1 \pm 0.4$ \\
\hline Sum otonecines bases & & $26 \pm \quad 3$ & $0.72 \pm 0.15$ & $36.5 \pm 8.4$ & $23.9 \pm 2.4$ \\
\hline Total & & $2339 \pm 119$ & $9.71 \pm 1.34$ & $425.3 \pm 99.5$ & $65.2 \pm 16.6$ \\
\hline
\end{tabular}


Table 3. Total PA concentrations in urine and faeces samples collected after the morning milking (potential metabolites excluded). Urine samples were treated with deconjugation enzymes.

\begin{tabular}{lrrrrr}
\hline Day & Cow 1 & Cow 2 & Cow 3 & mean & SD \\
\hline Urine $\left(\mu \mathrm{g} \mathrm{l}^{-1}\right)$ & & & & & \\
2 & 0 & 0 & 0 & 0 & 0 \\
5 & 1 & 0 & 0 & 0 & 0 \\
9 & 109 & 80 & 133 & 107 & 27 \\
12 & 91 & 66 & 162 & 106 & 49 \\
16 & 231 & 111 & 266 & 203 & 82 \\
19 & 234 & 137 & 227 & 200 & 54 \\
22 & 339 & 219 & 519 & 359 & 151 \\
26 & 322 & 526 & 461 & 436 & 104 \\
30 & 5 & 10 & 6 & 7 & 3 \\
33 & 0 & 0 & 0 & 0 & 0 \\
\hline Faeces $\left(\mu \mathrm{g} \mathrm{kg}^{-1}\right)$ & & & & \\
2 & 0 & 0 & 0 & 0 & 0 \\
5 & 0 & 0 & 0 & 0 & 0 \\
9 & 14 & 44 & 15 & 24 & 17 \\
12 & 16 & 19 & 28 & 21 & 6 \\
16 & 28 & 33 & 50 & 37 & 11 \\
19 & 25 & 43 & 50 & 39 & 13 \\
22 & 44 & 77 & 68 & 63 & 17 \\
26 & 50 & 65 & 89 & 68 & 20 \\
30 & 5 & 13 & 8 & 8 & 4 \\
33 & 0 & 0 & 0 & 0 & 0 \\
\hline
\end{tabular}




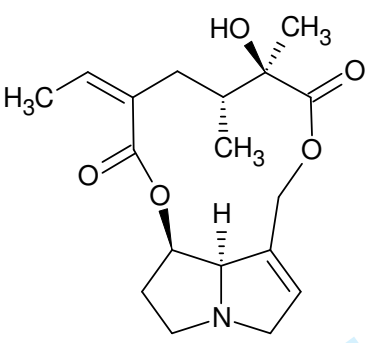

Senecionine

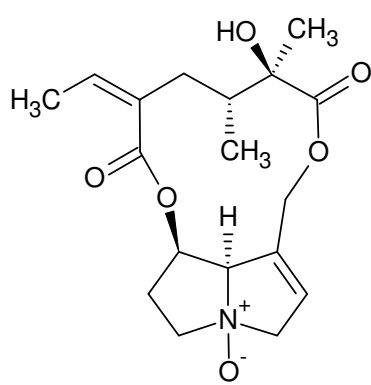

Senecionine $\mathrm{N}$-oxide

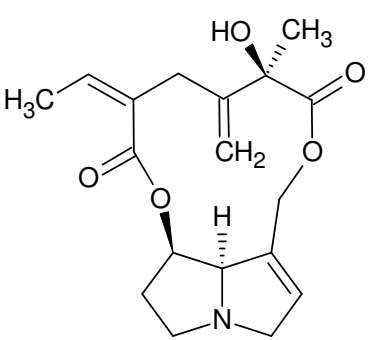

Seneciphylline

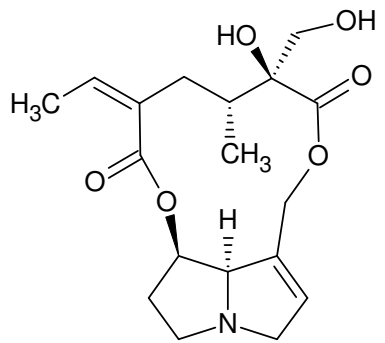

Retrorsine

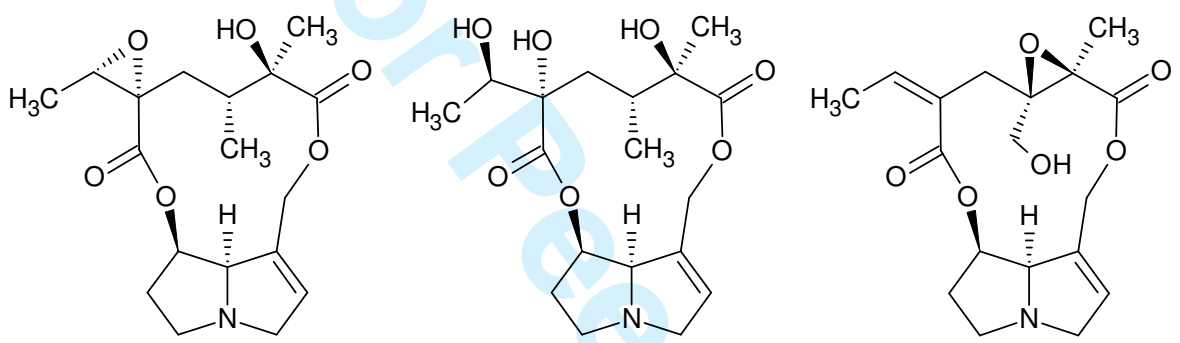

Jacobine<smiles>C/C=C1/C[C@@H](C)[C@@H](O)[C@@H](C)C(=O)OCC2=CCN(C)CC[C@@H](OC1=O)C2=O</smiles>

Senkirkine

Figure 1. 


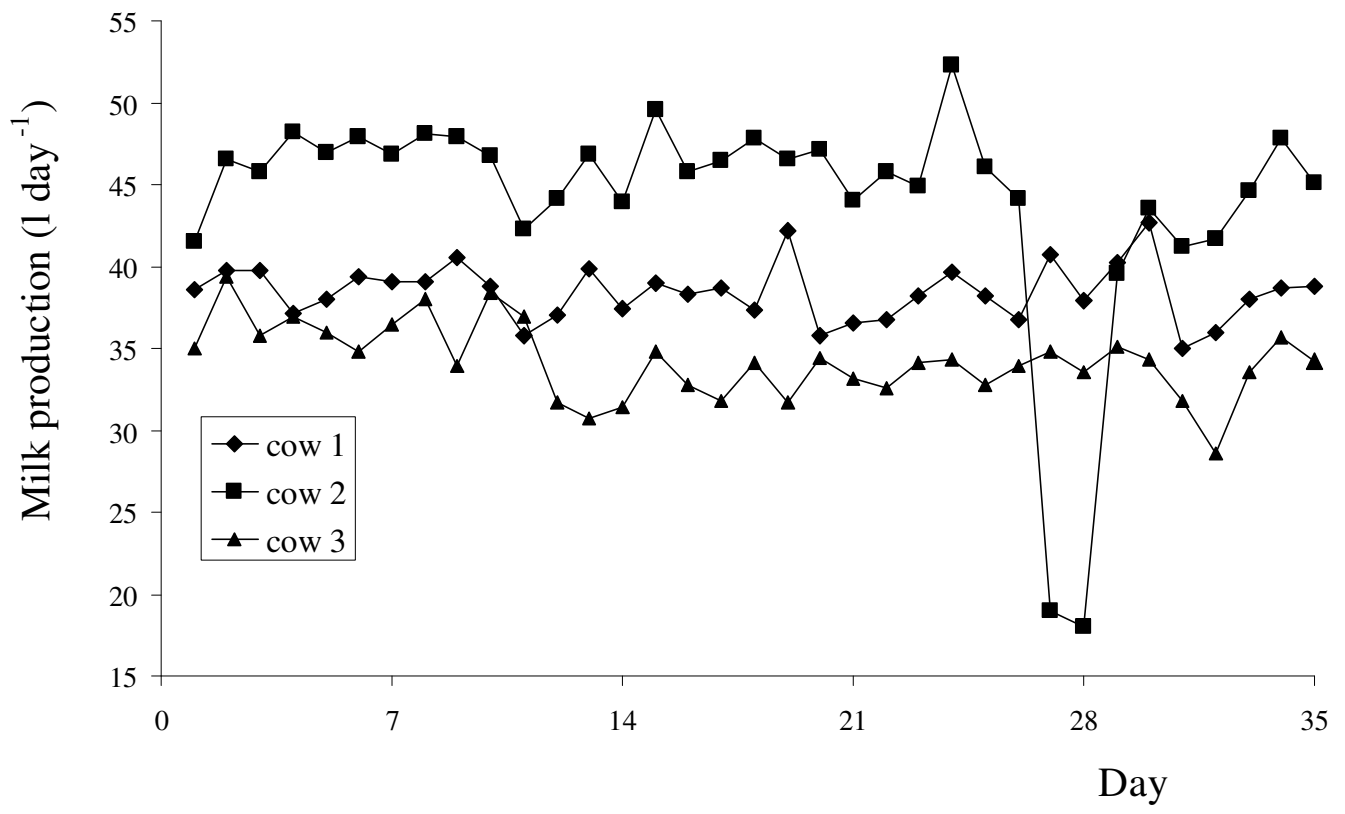

Figure 2. 

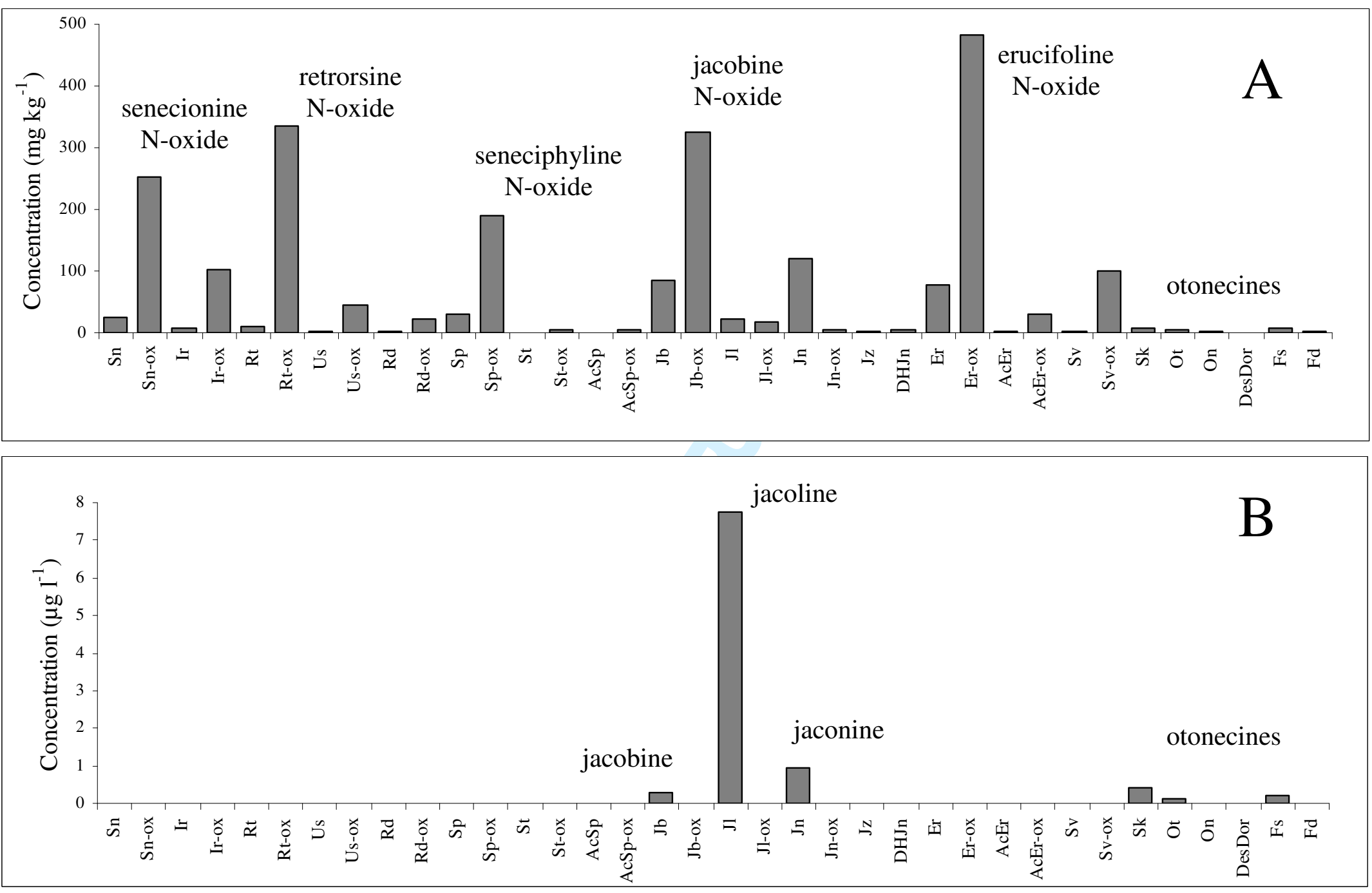

http://mc.manuscriptcentral.com/tfac Email: fac@tandf.co.uk 

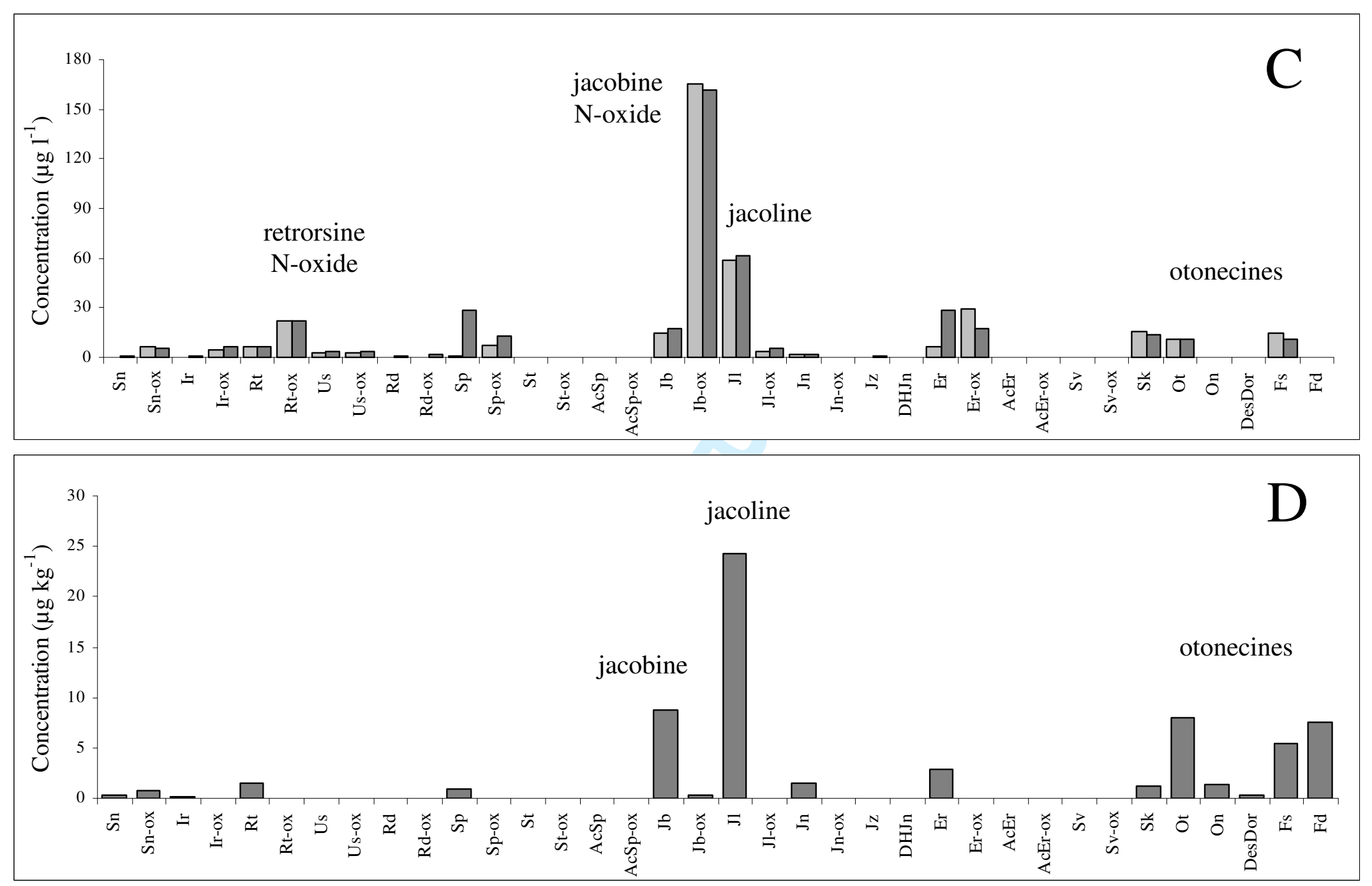

Figure 3. 

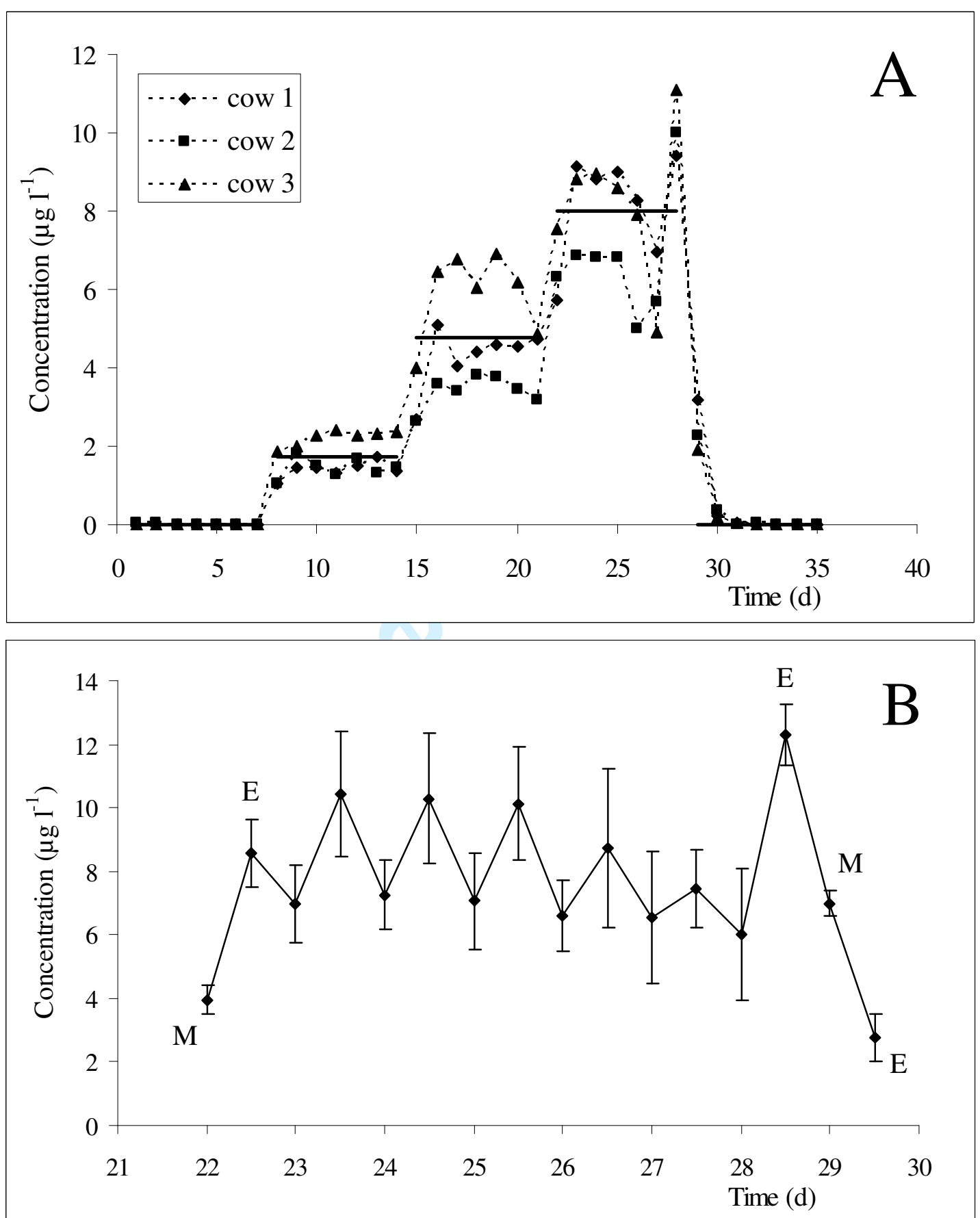

Figure 4. 

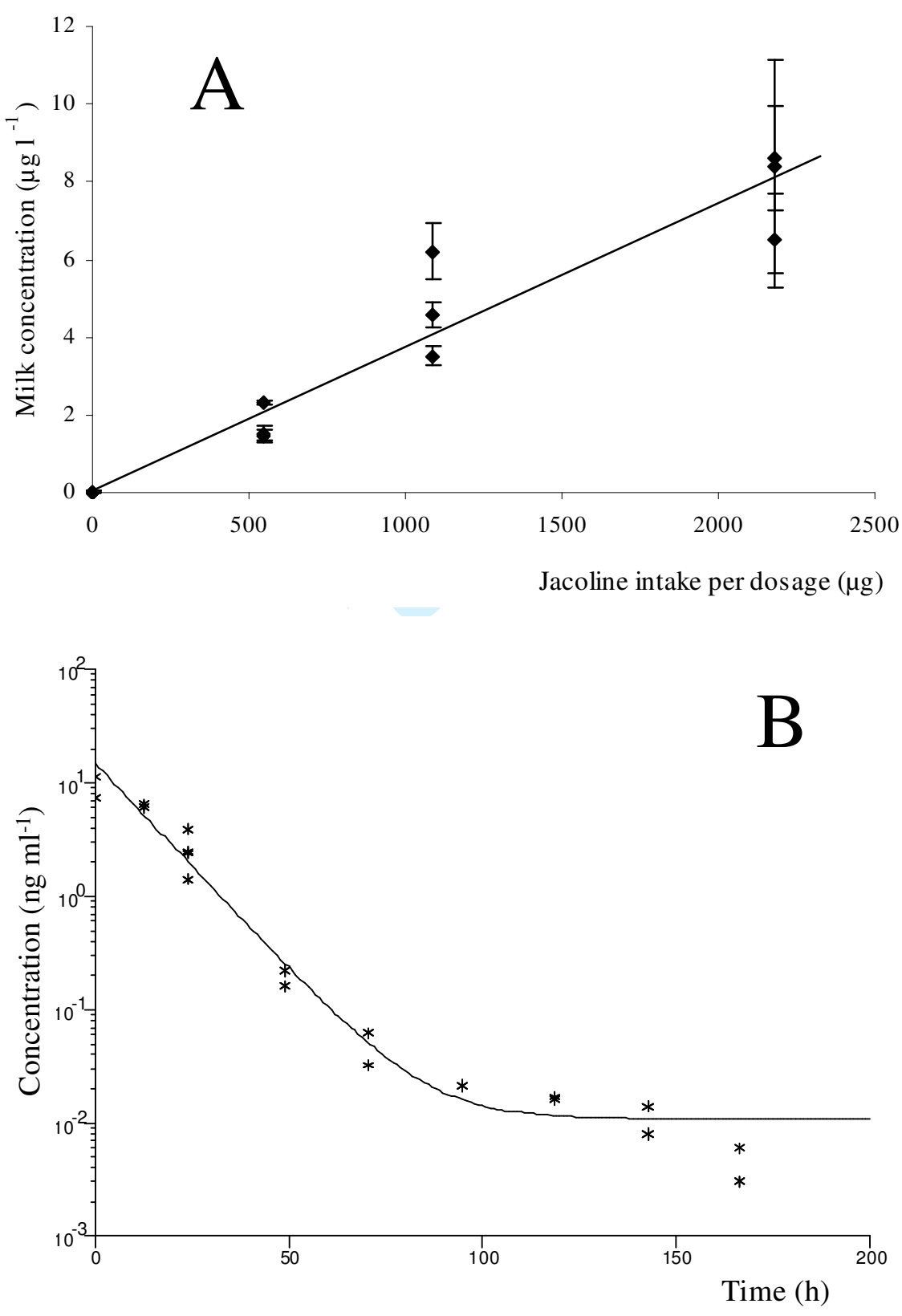

Figure 5. 